Article

\title{
Green Extraction Methods for Active Compounds from Food Waste-Cocoa Bean Shell
}

\author{
Nika Pavlović ${ }^{1}$, Stela Jokić ${ }^{2}$, Martina Jakovljević ${ }^{2}$, Marijana Blažić ${ }^{3}$ and Maja Molnar ${ }^{2, *}$ \\ 1 Faculty of Medicine Osijek, Josip Juraj Strossmayer University of Osijek, Josipa Huttlera 4, 31000 Osijek, \\ Croatia; nika.felicita@gmail.com \\ 2 Faculty of Food Technology Osijek, Josip Juraj Strossmayer University of Osijek, Franje Kuhača 20, \\ 31000 Osijek, Croatia; stela.jokic@ptfos.hr (S.J.); martina.jakovljevic@ptfos.hr (M.J.) \\ 3 Karlovac University of Applied Sciences, Trg J. J. Strossmayera 9, 47000 Karlovac, Croatia; \\ marijana.blazic@vuka.hr \\ * Correspondence: maja.molnar@ptfos.hr; Tel.: +385-98-918-2391; +385-31-224-342
}

Received: 16 January 2020; Accepted: 28 January 2020; Published: 30 January 2020

\begin{abstract}
This is the first report on the extraction of cocoa bean shell (CBS) using deep eutectic solvents (DESs). Screening results with 16 different choline chloride-based DESs showed how choline chloride:oxalic acid DES was the most suitable solvent for the extraction of the bioactive compounds from CBS and that concentrations varied greatly depending on the used solvent. The DES extraction was compared to the DESs coupled with microwave extraction (MAE), and the yields of the extracted compounds were higher for DES/MAE. For theobromine, the obtained yields for DES extraction were $2.145-4.682 \mathrm{mg} / \mathrm{g}$, and for caffeine, were $0.681-1.524 \mathrm{mg} / \mathrm{g}$, whereas for DES/MAE, the same compounds were obtained in $2.502-5.004 \mathrm{mg} / \mathrm{g}$ and $0.778-1.599 \mathrm{mg} / \mathrm{g}$. Antioxidant activity was also determined, using DPPH method, obtaining 24.027-74.805\% activity for DES extraction and 11.751-55.444\% for DES/MAE. Water content significantly influenced the extraction of targeted active compounds from CBS, whereas extraction time and temperature did not show statistically significant influence. The extraction temperature only influenced antioxidant activity. The study demonstrated how extraction using DES and microwaves could be of a great importance in the future trends of green chemistry for the production of CBS extracts rich in bioactive compounds.
\end{abstract}

Keywords: cocoa bean shell; waste; deep eutectic solvents; microwave-assisted extraction; active compounds

\section{Introduction}

To minimize food waste during processing of raw materials, a new age tendency is to transform it into valuable products with certain nutritional value. Cocoa bean shell (CBS) is just one of these food industry by-products, which contains a number of bioactive compounds that can be extracted and used for different purposes. In the production of chocolate and its products, the CBS is removed from the cocoa bean cotyledons, during the pre-roasting or after the roasting process. In the fermentation, roasting, and alkalization process, some bioactive compounds, like theobromine and phenols, can migrate from cocoa bean to CBS [1,2]. Thus, enriched CBS could potentially be an interesting ingredient in other production processes [1].

The chemical composition of CBS mostly depends on the origin of Theobroma cacao L. and its processing. Okyama et al. [2] in their review study mentioned Africa, America, Asia, and Oceania as the major parts in the world for the production of cocoa beans.

The basic composition, however, includes dietary fibers; carbohydrates; methylxantines, like theobromine (3,7-dimethylxantine), caffeine (1,3,7-trimethylxantine), and theophylline 
(1,3-dimethylxantine); fats; and some phenolic compounds. CBS possesses a high nutritive value, but due to the high theobromine and caffeine content, its utilization in animal feeds is limited [3-5]. Nevertheless, it has been used as a goat feed [6], fish feed [7,8], pig feed [9], and as adsorbent for wastewater treatment [10]. Some authors used it as a fortification agent in corn snack products [11], whereas it has also been used as a flour in muffin and biscuit production [12,13]. CBS extracts can also find a numerous interesting applications, such as the application in oral care, due to their anti-cariogenic activity [14] and inhibition of plaque deposition [15]. As the CBS is rich in fibers and has a certain nutritional value, it was demonstrated that its nutritional effects include a good effect of children idiopathic constipation [16] and reduce the food intake as well as body weight gain [12,13]. Therefore, its potential applications in food industry are numerous. Theobromine, as one of the most abundant compounds of CBS, possesses some pharmacological properties such as diuretic, cardiac stimulant, smooth-muscle relaxant, anticancer, hypocholesterolemic, asthma, and coronary vasodilator activity [3], whereas caffeine and theophylline possess a similar psychoactive activity [2]. Caffeine accelerates the heart rate and raises blood pressure, whereas adverse effects could be manifested as insomnia, nervousness, tachycardia, arrhythmia, elevated respiration, and gastrointestinal disturbances [17]. The main fatty acids in CBS are palmitic, stearic, and oleic acid, similar to the fat content of cocoa butter, and also with twice as much of linoleic acid in CBS [2]. Most abundant polyphenols in CBS are epicatechin and catechin [18] and some phenolic acids like gallic and chlorogenic acid [19].

All of the above-mentioned active compounds can be extracted from the CBS employing various extraction tehniques. Okiyama et al. [20] extracted catehin, epicatehin, theobromine, and caffeine by pressurized liquid extraction with ethanol. Karim et al. [21] performed an extraction of CBS by aqueous ethanol to determine an antioxidant potential of such extracts, whereas Grillo et al. [22] extracted theobromine and caffeine using 30:49:21 $\mathrm{Hex} / \mathrm{EtOH} / \mathrm{H}_{2} \mathrm{O}$ mixture. Nguyen and Nguyen [23] were able to extract theobromine from the cocoa shell with $70 \%$ ethanol, and to obtain the highest possible yield, the purification was carried out with $10 \%$ lead acetate solution. Arlorio et al. [24] found caffeine in $\mathrm{CO}_{2}$ extracts of CBS. Jokić et al. [19] explored subcritical water extraction (SWE) of CBS to extract specific bioactive compounds. Pavlović et al. [25] provided insight into the bioactive compound profile in CBS extracts, obtained by supercritical $\mathrm{CO}_{2}$ extraction, ultrasound-assisted extraction (UAE), high-voltage electric discharge extraction (HVED), and DESs. This research is a continuation of our efforts in the application of green technologies in extraction of plant bioactive compounds, more specifically in extraction of bioactive compounds from CBS.

To achieve the most efficient extraction for the selected compounds, critical input parameters should be included: the nature of plant matrix, chemistry of bioactive compounds of our interest, used solvent, applied process parameters, as well as scientific expertise [26]. The environmentally friendly character of deep eutectic solvents (DESs) is accomplished through the utilization of nontoxic, biodegradable, cheap compounds that are used in their formation, as well as the DESs low vapor pressure and recyclability. It is a mixture of two or more compounds with a lower melting point than the melting points of each compound individually. One of the interesting features of these types of solvents is the possibility of making a large number of eutectic mixtures with different chemical and physical properties, due to changing one or both compounds [27]. In general, DESs have shown a great potential as the extracting solvents for different bioactive compounds from various plants. DESs have already been successfully utilized in the extraction of phenolic compounds from olive oil [28], from grape skin [29], phenolic compounds from Barsonima intermedia leaves [30], rutin from Sophora japonica [31], or Ruta graveolens [32]. Due to the scarcely applied DES extraction of some alkaloids from herbal medicine, Jiang et al. [33] tailored 75 types of DESs for the extraction of bioactive alkaloids and remarked how the developed DES extraction method was efficient and green. DES can be successfully utilized as such or in a combination with microwave-assisted extraction (MAE) [27]. Azmir et al. [26] mentioned studies describing some MAE advantages like quicker heating, reduced thermal gradients and increased extract yield. In DES/MAE extraction, DES acts in the way to absorb microwave radiation and to disrupt cell walls, which enables compounds to release from the sample matrix. This uniform 
energy transfer gives a shorter extraction time as well as low solvent consumption, which makes it a powerful separation technique [34].

To address the environmentally friendly extraction protocols, we have employed DESs for the extraction of different constituents of CBS, as well as the combination of DESs and MAE extraction techniques on the same matrix. In distinction from the existing papers, the present research provides novelty with respect to (a) detail extraction of cocoa bean shell (CBS) using deep eutectic solvents (DESs) enhanced by microwave-assisted extraction (MAE); (b) High Performance Liquid Chromatography (HPLC) analysis of methylxantines and polyphenols in obtained extracts; and (c) optimization of the main extraction parameters using response surface methodology (RSM), based on the antioxidant capacity and the concentration of each individually selected active compound.

\section{Materials and Methods}

\subsection{Material}

Cocoa bean shell (CBS) material was obtained from Kandit d.o.o. Chocolate Factory, Osijek, Croatia, in the summer of 2017. Before it was delivered from the factory, CBS was primarily separated from the cotyledon after the roasting process which was done at $135^{\circ} \mathrm{C}$ for $55 \mathrm{~min}$. The countries of geographical origin of CBS were Ghana, Cameroon, Nigeria, New Guinea and Ivory Coast and this is known as West Africa blend.

All chemicals (standards and organic solvents) were purchased from commercial suppliers and were of analytical grade. Solvents were purchased from J.T. Baker (Phillipsburg, USA). All standards for HPLC analysis, including theobromine standard (purity $\geq 98 \%$ ), theophylline (purity $\geq 99 \%$ ), gallic acid (purity $\geq 99 \%$ ), epicatechin (purity $\geq 98 \%$ ), catechin (purity $\geq 99 \%$ ), and caffeic acid (purity $\geq 99 \%$ ), were purchased from Sigma Aldrich (Germany), whereas the caffeine standard ( $\geq 98 \%$ ) was purchased from Dr. Ehrenstorfer (Augsburg, Germany). DPPH radical was purchased from Sigma-Aldrich (St. Louis, MI, USA).

\subsection{Preparation of Deep Eutectic Solvents (DES)}

DESs were prepared according to our previous work [35]. Choline chloride as a hydrogen bond acceptor (HBA) was mixed with different hydrogen bond donors (HBD), as indicated in the Table 1. The mixture was stirred and heated at $80{ }^{\circ} \mathrm{C}$ until a clear liquid was formed and used in further extraction experiments as such.

Table 1. Screening results for different Deep Eutectic Solvents (DESs) at different \% of water, at constant time of $60 \mathrm{~min}$ and temperature $50^{\circ} \mathrm{C}$.

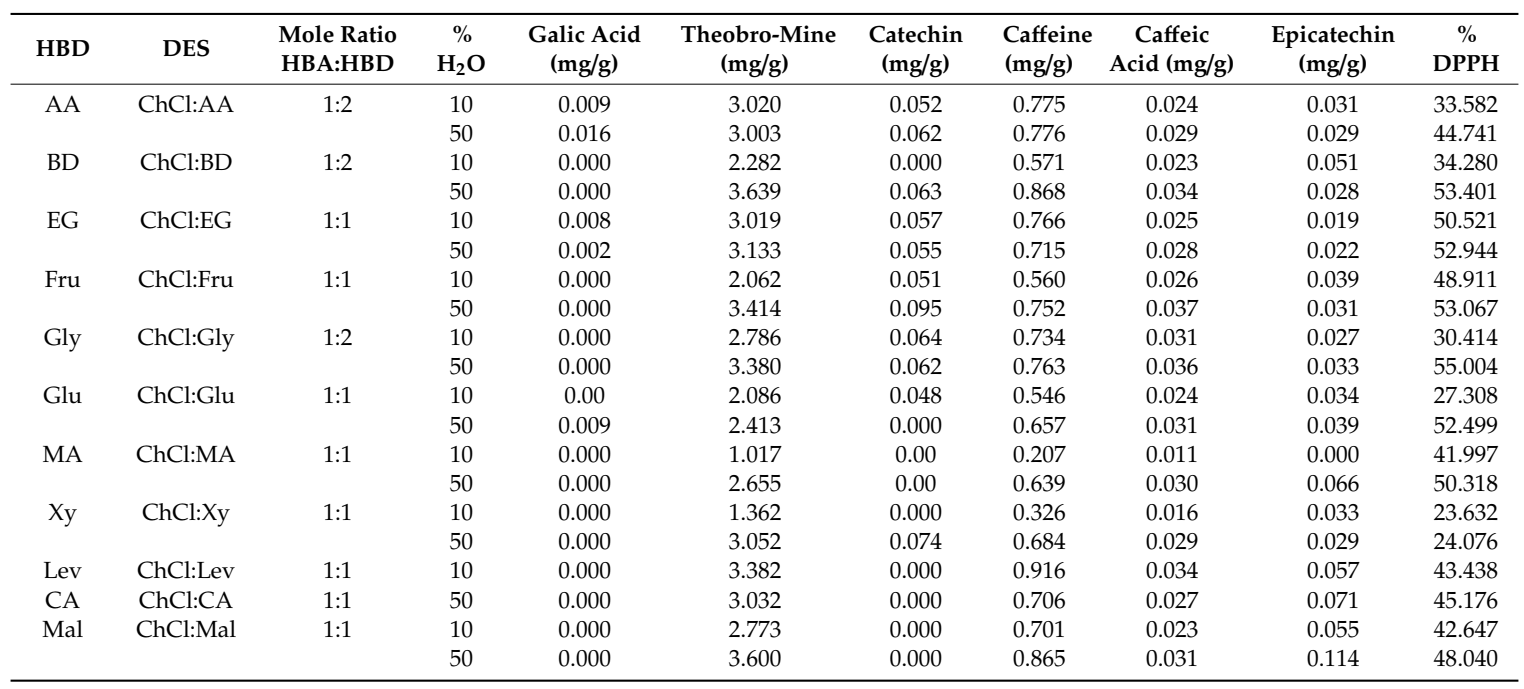


Table 1. Cont.

\begin{tabular}{|c|c|c|c|c|c|c|c|c|c|c|}
\hline HBD & DES & $\begin{array}{l}\text { Mole Ratio } \\
\text { HBA:HBD }\end{array}$ & $\begin{array}{c}\% \\
\mathrm{H}_{2} \mathrm{O}\end{array}$ & $\begin{array}{c}\text { Galic Acid } \\
\text { (mg/g) }\end{array}$ & $\begin{array}{c}\text { Theobro-Mine } \\
\text { (mg/g) }\end{array}$ & $\begin{array}{c}\text { Catechin } \\
(\mathrm{mg} / \mathrm{g})\end{array}$ & $\begin{array}{l}\text { Caffeine } \\
\text { (mg/g) }\end{array}$ & $\begin{array}{c}\text { Caffeic } \\
\text { Acid (mg/g) }\end{array}$ & $\begin{array}{c}\text { Epicatechin } \\
(\mathrm{mg} / \mathrm{g})\end{array}$ & $\begin{array}{c}\% \\
\text { DPPH }\end{array}$ \\
\hline \multirow[t]{2}{*}{ LA } & ChCl:LA & $1: 1$ & 10 & 0.000 & 3.145 & 0.000 & 0.790 & 0.036 & 0.059 & 39.654 \\
\hline & & & 50 & 0.000 & 2.854 & 0.000 & 0.665 & 0.026 & 0.063 & 51.524 \\
\hline \multirow[t]{2}{*}{$\mathrm{OA}$} & ChCl:OA & 1:1 & 10 & 0.000 & 0.620 & 0.000 & 0.156 & 0.000 & 0.000 & 64.322 \\
\hline & & & 50 & 0.000 & 3.605 & 0.000 & 0.909 & 0.019 & 0.104 & 66.307 \\
\hline Sor & ChCl:Sor & 1:1 & 50 & 0.000 & 3.008 & 0.062 & 0.635 & 0.040 & 0.110 & 32.153 \\
\hline \multirow[t]{2}{*}{$\mathrm{U}$} & ChCl:U & $1: 2$ & 10 & 0.000 & 2.329 & 0.000 & 0.665 & 0.028 & 0.022 & 31.148 \\
\hline & & & 50 & 0.000 & 3.613 & 0.069 & 0.848 & 0.037 & 0.011 & 50.462 \\
\hline $\mathrm{TA}$ & $\mathrm{ChCl:TA}$ & 1:1 & 10 & 0.000 & 2.056 & 0.000 & 0.642 & 0.026 & 0.030 & 46.298 \\
\hline
\end{tabular}

DES: Deep eutectic solvent; $\mathrm{ChCl}$ : Choline chloride; AA: Acetamide, BD: Butan 1,4-diole; EG: Ethylene glycol; Fru: Fructose; Gly: Glycerole; Glu: Glucose; MA: Malic acid; Xy: Xylitole; Lev: Levulinic acid; CA: Citric acid; Mal: Malonic acid; LA: lactic acid; OA: Oxalic acid; Sor: Sorbitol; U: Urea; TA: Tartaric acid; HBA: Hydrogen Bond Acceptor; HBD: Hydrogen Bond Donor; \% DPPH: \% radical-scavenging activity.

\subsection{Extraction of Bioactive Compounds from CBS}

Prior to the extraction, CBS was grounded on the standard laboratory mill. The extraction of CBS was performed by weighting $50 \mathrm{mg}$ of the grinded CBS in the centrifuge tube vial and adding $1 \mathrm{~mL}$ of the solvent $\left(10 \%\right.$ or $50 \% \mathrm{H}_{2} \mathrm{O} / \mathrm{DES}$ mixture). The extraction was performed at $50{ }^{\circ} \mathrm{C}$ during $60 \mathrm{~min}$ and by stirring. Afterwards, the extracts were centrifuged and decanted. Screening analysis was performed in sixteen different choline chloride-based DESs, where choline chloride was combined with different hydrogen bond donors according to the Table 1. Furthermore, when the best DES was chosen for this type of extraction, 17 runs, including five replicates, were performed according to the Box-Behnken design by RSM (Table 2) [35].

Table 2. Determined active compounds and antioxidant activity in extracts performed with Deep Eutectic Solvent (DES) and stirring.

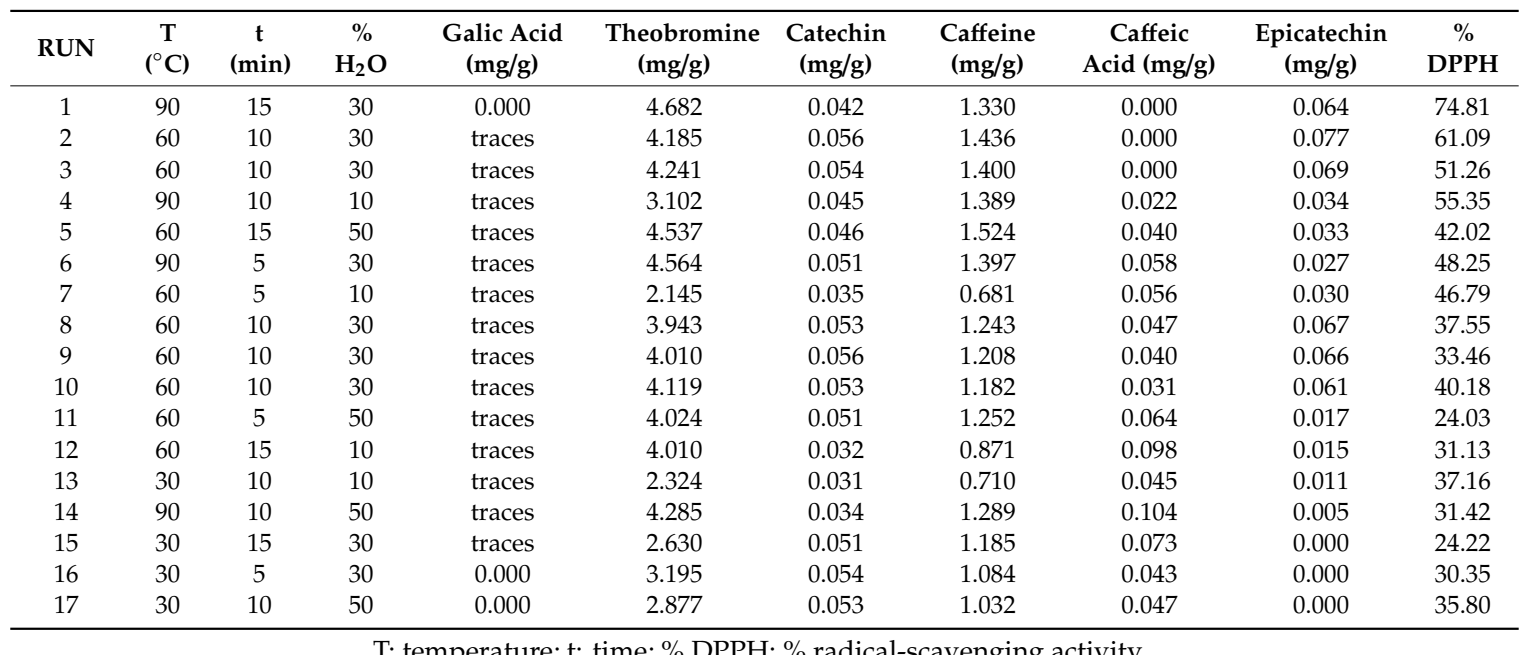

\subsection{DESs Extraction Coupled with MAE}

The extraction of bioactive compounds from Theobroma cacao L. CBS, a byproduct in the production of cocoa and its products, by DES extraction coupled with microwave-assisted extraction (MAE) was performed using Milestone flexiWAVE (Milestone Srl, Sorisole (BG), Italy) microwave system, equipped with rotating carousel with 15 positions for PTFE high-pressure vessels. The microwave power was set to $600-800 \mathrm{~W}$. A $500 \mathrm{mg}$ of CBS was weighted in the high-pressure vessel, followed by the addition of $10 \mathrm{~mL}$ of the solvent $\left(10 \%\right.$ or $50 \% \mathrm{H}_{2} \mathrm{O} / \mathrm{DES}$ mixture). All extraction experiments were performed at the same extraction conditions as the DES extraction with stirring (Table 3). 
Table 3. Determined active compounds and antioxidant activity in extracts obtained DES under microwaves.

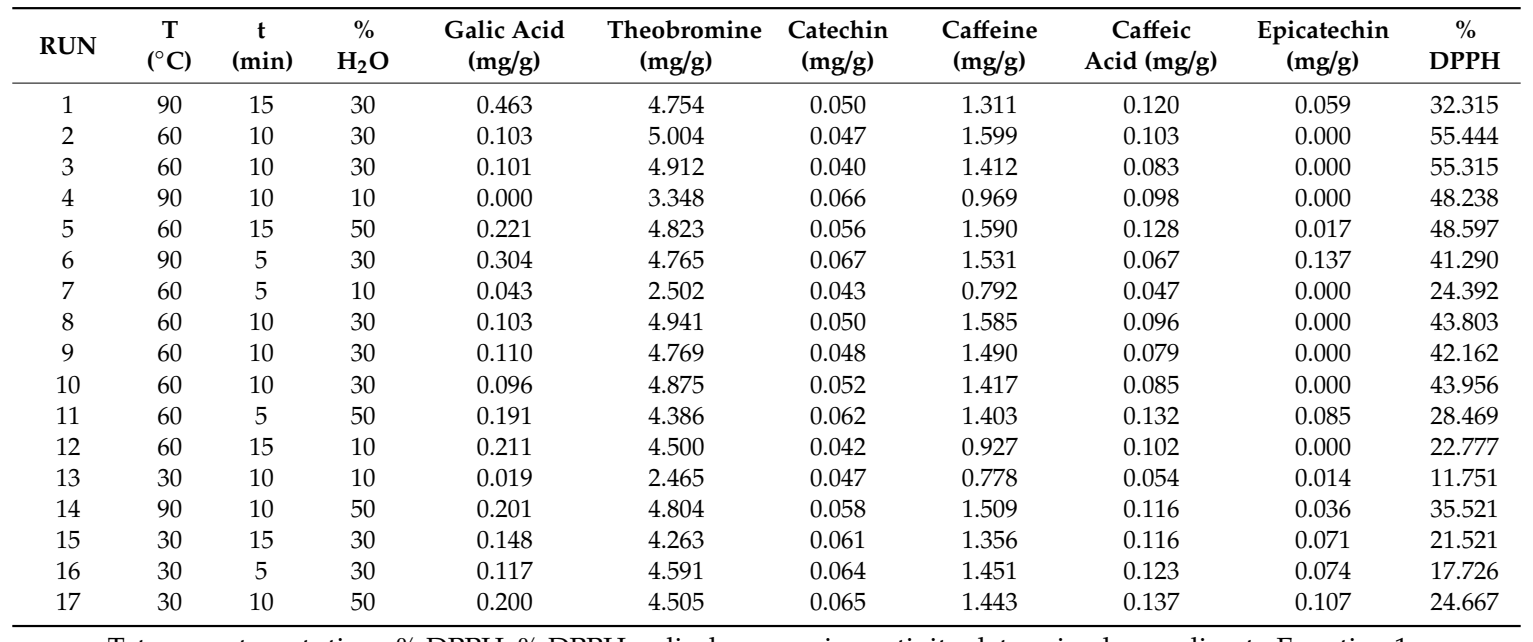

T: temperature; t: time; \% DPPH: \% DPPH radical-scavenging activity determined according to Equation 1.

\subsection{HPLC Analysis}

Identification and quantification of bioactive compounds in CBS extracts was done according to modified Alves de Oliveira Nascimento et al. [36] study. After the extraction, and prior to HPLC analysis, extracts were diluted 1:10 with water and filtered through $0.2 \mu \mathrm{m}$ polytetrafluoroethylene (PTFE) syringe filter. The measurement was done on the High-Performance Liquid Chromatograph (HPLC) (Infinity 1260 Agilent Technologies, Santa Clara, USA), which contained an autosampler G7129A, quaternary pump G7111B 1260, and diode array detector (DAD) G7117C 1260 DAD HS. A column used was Zorbax $C_{18} 150 \mathrm{~mm} \times 4.6 \mathrm{~mm} \times 5 \mu \mathrm{m}$, which was thermostated on $30^{\circ} \mathrm{C}$. The wavelength used for the measurement was $276 \mathrm{~nm}$ while the injection volume was set to $20 \mu \mathrm{L}$. A gradient mobile phase was used, starting by $1 \%$ formic acid and acetonitrile (95:5) at the beginning, changing to (80:20) till $9 \mathrm{~min}$, and returning to (95:5) till $13 \mathrm{~min}$. The flow of the mobile phase was set to $1 \mathrm{~mL} / \mathrm{min}$, and the analysis was performed in triplicate.

\subsection{DPPH Scavenging Activity}

Antioxidant activity of the obtained CBS extracts was determined using DPPH radical. The solution mix for the measurement was prepared by adding $1.2 \mathrm{~mL}$ of a CBS extract $(10 \mathrm{mg} / \mathrm{mL})$ and $0.5 \mathrm{~mL}$ of $0.2 \mathrm{mM}$ DPPH solution freshly prepared in methanol.

After $30 \mathrm{~min}$ of incubation in the dark and at ambient temperature, the apsorbance (A) was measured at $517 \mathrm{~nm}$ on the UV-Visible Spectrophotometer (Termo Spectronic, Cambridge, Great Britain) and DPPH scavenging activity was determined according to the Equation (1):

$$
\% D P P H=\frac{\left(A_{D P P H}+A_{b}\right)-A_{s}}{A_{D P P H}} * 100
$$

where $A_{\mathrm{DPPH}}$ was the absorbance of the control (instead of the sample, methanol was added); $A_{\mathrm{b}}$ was the absorbance of the sample, where instead of DPPH methanol was added and $A_{\mathrm{s}}$ was the absorbance of the sample mixed with DPPH radical solution [37]. All measurements were performed in triplicate.

\subsection{Statistical Analysis}

The commercial Design-Expert ${ }^{\circledR}$ software (ver. 9, Stat-Ease Inc., Minneapolis, MN, USA) was used for the statistical analysis of obtained experimental data. To estimate the quality of the obtained models, the analysis of variance (ANOVA) was used. The test of the statistically significant difference was based 
on the total error criteria with the level of confidence of $95.0 \%$. The response plots were generated using the same software for better understanding the correlation of independent and response variables.

\section{Results}

\subsection{DES Extraction of Bioactive Compounds from CBS}

This research is the first detailed report on the extraction of CBS using DESs. In our previously study [25], only a short insight into DES extraction was given, where only one DES was described, namely, choline chloride:oxalic acid (0,25, and 50\% of water and 60, 180, and $360 \mathrm{~min}$ ). There we indicated that the time of $60 \mathrm{~min}$ is sufficient for the extraction of bioactive compounds from plant material (theobromine $3.700 \mathrm{mg} / \mathrm{g}$ and $3.644 \mathrm{mg} / \mathrm{g}$, and caffeine $0.507 \mathrm{mg} / \mathrm{g}$ and $0.536 \mathrm{mg} / \mathrm{g}$ with $25 \%$ and $50 \% \mathrm{H}_{2} \mathrm{O}$ ), whereas the energy consumption during heating is also reduced in shorter time. Furthermore, some of the DES possess a high viscosity at room temperature, which can be reduced by the increased temperature and the addition of water. Both thermolabile compounds and DES can be degraded at high temperatures, so the temperature of $50^{\circ} \mathrm{C}$ was applied. Hereby, in this paper, we investigated a larger number of DESs, followed by the optimization of the process parameters.

In general, DESs can be formed from various HBAs and HBDs, and their combination, as well as the ratio, affects their physical and chemical properties greatly. Due to the different chemical and physical properties, they can exhibit a different extraction potential of various bioactive compounds. Therefore, an extraction of selected compounds in this study was performed in 16 different DESs. Our research was conducted utilizing choline chloride based DESs, where choline chloride was combined with different HBDs, as indicated in the Table 1 . A screening was performed with the addition of water to each DESs $(10 \%$ and $50 \% \mathrm{v} / \mathrm{v})$ for $60 \mathrm{~min}$, at temperature of $50^{\circ} \mathrm{C}$.

A screening experiment revealed that the extracted amount of bioactive compounds varied greatly depending on the type of the solvent, as expected. Gallic acid was extracted only with $\mathrm{ChCl}$ :AA (0.009 and $0.016 \mathrm{mg} / \mathrm{g}), \mathrm{ChCl}$ :EG (0.008 and $0.002 \mathrm{mg} / \mathrm{g}$ ) and ChCl:Glu $(0.009 \mathrm{mg} / \mathrm{g})$. The highest content of theobromine was extracted with ChCl:BD (3.639 mg/g), ChCl:OA (3.605 mg/g), and ChCl:U $(3.613 \mathrm{mg} / \mathrm{g})$ with $50 \%$ of water, whereas the lowest amount of theobromine was extracted with $\mathrm{ChCl}: \mathrm{OA}(0.620 \mathrm{mg} / \mathrm{g})$ with $10 \%$ of water. Catechin was extracted in the highest amount with $\mathrm{ChCl}$ :Fru $(0.095 \mathrm{mg} / \mathrm{g})$ with $50 \%$ of added water, whereas ChCl:MA, ChCl:Lev, ChCl:CA, ChCl:Mal, ChCl:LA, $\mathrm{ChCl}: \mathrm{OA}$, and ChCl:TA yielded no catechin. Caffeine was found in the highest amount when extracted with $\mathrm{ChCl}: \mathrm{OA}(0.909 \mathrm{mg} / \mathrm{g})$ with $50 \%$ of water and ChCl:Lev $(0.916 \mathrm{mg} / \mathrm{g})$ with $10 \%$ of water, and in the lowest amount in ChCl:OA $(0.156 \mathrm{mg} / \mathrm{g})$ with $10 \%$ of water. Caffeic acid was the most abundant in the ChCl:Sor $(0.04 \mathrm{mg} / \mathrm{g})$ with $50 \%$ of water and in the lowest concentration with ChCl:OA $(0 \mathrm{mg} / \mathrm{g})$ with $10 \%$ of water. The amount of epicatechin was the highest in ChCl:Mal $(0.114 \mathrm{mg} / \mathrm{g})$ with $50 \%$ of water, whereas the lowest was in ChCl:OA $(0 \mathrm{mg} / \mathrm{kg})$ with $10 \%$ of water. Futhermore, the best antioxidant activity, expressed as DPPH scavenging activity, was obtained with $\mathrm{ChCl:OA}, 66.307 \%$ with $50 \%$ of water and $64.322 \%$ with $10 \%$ of water. When compared to the ultrasound assisted water extraction of CBS, performed in our previous research [25], obtaining theobromine yield of 4.44-5.61 mg/g and caffeine content of $0.537-0.591 \mathrm{mg} / \mathrm{g}$, we can conclude that DESs possess a comparable efficacy for the extraction of selected compounds.

Given all the data, and the fact that some compounds are not always desirable in the obtained extracts, we have decided to optimize the extraction conditions of selected compounds in ChCl:OA DES. This DES was chosen because the influence of the water addition on the amount of bioactive compounds was the highest, thus being the most suitable for tuning the parameters for extraction of desired compounds. Therefore, both CBS extracts, with either high or low theobromine or caffeine content, can be obtained with the same solvent, only varying the water content and based on this parameter one can tune the desirable properties of the selected DES. Furthermore, the capability of the solvent to extract different undesirable compounds from the material, offers an opportunity for 
these solvents to be used in the pretreatment process of the material prior to its further utilization for different purposes.

The optimization of the extraction parameters was performed in a combination of 17 different experiments according to BBD, varying the temperature, extraction time, and the amount of water. Furthermore, for comparison, all experiments were performed by stirring (Table 2) and under microwaves (Table 3), applying the same DES and process parameters.

Above all, the results represented in Tables 2 and 3 showed how DES extraction coupled with MAE gave slightly higher concentrations of selected bioactive compounds in CBS extracts. Some compounds that were found in traces after DES extraction, gave better yields after using DES/MAE, like gallic acid. These results were expected, as it is well established that the application of microwaves in many chemical processes, including extraction, can enhance the yield, shorten the reaction time, and reduce the overall energy consumption. This is well explained by the thermal and non-thermal effects of the microwaves explained in detail by de la Hoz, Diaz-Ortiz, and Moreno [38]. Furthermore, by observing the obtained concentrations of those bioactive compounds (Tables 2 and 3) it is noticeable how different parameters variously influence on the amount of every specific compound. The highest theobromine and caffeine concentrations were found by applying $60^{\circ} \mathrm{C}$ and $30 \%$ of water during $10 \mathrm{~min}$ of extraction time $(5.004 \mathrm{mg} / \mathrm{g}$ and $1.599 \mathrm{mg} / \mathrm{g})$, as well as the highest DPPH scavenging activity $(55.444 \%)$. There are many data in the literature describing the amount of available theobromine in the CBS. Adamafio [39] stated in his review how theobromine content in CBS can vary from 5-21 mg/g according to different authors. Arlorio et al. [40] determined the amount of theobromine in cocoa hulls, which was $12.9 \pm 1.8 \mathrm{mg} / \mathrm{g}_{\text {d.w. }}$, whereas Sotelo and Alvarez [41] performed a water extraction and determined that the amount of theobromine in CBS was $0.223 \mathrm{mg} / \mathrm{g}$ of dry sample in fermented samples and $0.174 \mathrm{mg} / \mathrm{g}$ in not fermented samples, while caffeine was $0.056 \mathrm{mg} / \mathrm{g}$ in fermented, and $0.051 \mathrm{mg} / \mathrm{g}$ in non-fermented samples. Prabhakaran Nair [42] claims that the amount of theobromine in CBS is $1.3 \%$ and caffeine $0.1 \%$. Okiyama et al. [20] performed a pressurized liquid extraction with absolute ethanol and found that the amount of theobromine was $9.89 \pm 0.09 \mathrm{mg} / \mathrm{g}$, epicatechin $3.5 \pm 0.1 \mathrm{mg} / \mathrm{g}$, caffeine $1.44 \pm 0.01 \mathrm{mg} / \mathrm{g}$, and catechin $0.178 \pm 0.003 \mathrm{mg} / \mathrm{g}$. The highest content of caffeic acid in our research, was found by applying $30^{\circ} \mathrm{C}$ and $50 \%$ of water content, during $10 \mathrm{~min}$ of extraction time $(0.137 \mathrm{mg} / \mathrm{g})$, whereas catechin and epicatechin were 0.065 and $0.107 \mathrm{mg} / \mathrm{g}$, respectively.

\subsection{Response Surface Analysis and Process Optimization}

To investigate the influence of the process parameters on the extraction yield and antioxidant activity of selected compounds a response surface analysis was performed.

As gallic acid, theobromine, catechin, caffeine, and caffeic acid were obtained in higher yields applying DES with microwaves, the ANOVA was performed considering the DES/MAE of methylxantines, catechins, and antioxidant activity. The results are summarized in Table 4, Table 5, Table 6 and Table 7. For theobromine, only effect of water content in DES was significant $(p<0.05)$ in first order linear and quadratic effect $\left(X_{3}\right.$ and $\left.X_{3}{ }^{2}\right)$. The model F-value of 5.77 implies the model is significant, and a $p$-value of 0.0153 indicates that model terms are significant (Table 4 ).

Table 4. Analysis of variance (ANOVA) for the response surface quadratic model for theobromine.

\begin{tabular}{cccccc}
\hline Source & Sum of Squares & df & Mean Square & $\boldsymbol{F}$-Value & $\boldsymbol{p}$-Value \\
\hline Model & 9.16 & 9 & 1.02 & 5.77 & 0.0153 \\
$X_{1}$-Temperature & 0.4264 & 1 & 0.4264 & 2.42 & 0.1637 \\
$X_{2}$-Time & 0.5492 & 1 & 0.5492 & 3.12 & 0.1208 \\
$X_{3}$-Water content & 4.07 & 1 & 4.07 & 23.07 & 0.0020 \\
$X_{1 \times 2}$ & 0.0251 & 1 & 0.0251 & 0.1426 & 0.7169 \\
$X_{1 \times 3}$ & 0.0853 & 1 & 0.0853 & 0.4839 & 0.5091 \\
$X_{2} X_{3}$ & 0.6092 & 1 & 0.6092 & 3.46 & 0.1053 \\
$X_{1}{ }^{2}$ & 0.3531 & 1 & 0.3531 & 2.00 & 0.1998 \\
$X_{2}{ }^{2}$ & 0.0013 & 1 & 0.0013 & 0.0072 & 0.9348 \\
\hline
\end{tabular}


Table 4. Cont.

\begin{tabular}{cccccc}
\hline Source & Sum of Squares & df & Mean Square & $\boldsymbol{F}$-Value & $p$-Value \\
\hline$X_{3}{ }^{2}$ & 2.90 & 1 & 2.90 & 16.47 & 0.0048 \\
Residual & 1.23 & 7 & 0.1762 & & \\
Lack of Fit & 1.20 & 3 & 0.4010 & 52.72 & 0.0011 \\
Pure Error & 0.0304 & 4 & 0.0076 & & \\
Cor Total & 10.39 & 16 & & & \\
$R^{2}$ & 0.8813 & & & & \\
\hline
\end{tabular}

Table 5. Analysis of variance (ANOVA) for the response surface quadratic model for catechin.

\begin{tabular}{cccccc}
\hline Source & Sum of Squares & df & Mean Square & F-Value & $p$-Value \\
\hline Model & 0.0011 & 9 & 0.0001 & 3.80 & 0.0461 \\
$X_{1}$-Temperature & $2.000 \times 10^{-6}$ & 1 & $2.000 \times 10^{-6}$ & 0.0635 & 0.8083 \\
$X_{2}$-Time & 0.0001 & 1 & 0.0001 & 2.89 & 0.1327 \\
$X_{3}$-Water content & 0.0002 & 1 & 0.0002 & 7.34 & 0.0302 \\
$X_{1} X_{2}$ & 0.0000 & 1 & 0.0000 & 1.56 & 0.2524 \\
$X_{1} X_{3}$ & 0.0002 & 1 & 0.0002 & 5.37 & 0.0537 \\
$X_{2} X_{3}$ & $6.250 \times 10^{-6}$ & 1 & $6.250 \times 10^{-6}$ & 0.1985 & 0.6694 \\
$X_{1}{ }^{2}$ & 0.0005 & 1 & 0.0005 & 15.24 & 0.0059 \\
$X_{2} X_{3}^{2}$ & 0.0000 & 1 & 0.0000 & 0.7862 & 0.4047 \\
Residual & $3.603 \times 10^{-6}$ & 1 & $3.603 \times 10^{-6}$ & 0.1144 & 0.7451 \\
Lack of Fit & 0.0002 & 7 & 0.0000 & & \\
Pure Error & 0.0001 & 3 & 0.0000 & 2.20 & 0.2306 \\
Cor Total & 0.0001 & 4 & 0.0000 & & \\
$R^{2}$ & 0.0013 & 16 & & & \\
\hline
\end{tabular}

Table 6. Analysis of variance (ANOVA) for the response surface quadratic model for caffeine.

\begin{tabular}{cccccc}
\hline Source & Sum of Squares & $\mathbf{d f}$ & Mean Square & F-Value & $p$-Value \\
\hline Model & 1.15 & 9 & 0.1276 & 10.01 & 0.0031 \\
$X_{1}$-Temperature & 0.0107 & 1 & 0.0107 & 0.8361 & 0.3909 \\
$X_{2}$-Time & $6.125 \times 10^{-6}$ & 1 & $6.125 \times 10^{-6}$ & 0.0005 & 0.9831 \\
$X_{3}$-Water content & 0.7682 & 1 & 0.7682 & 60.26 & 0.0001 \\
$X_{1} X_{2}$ & 0.0039 & 1 & 0.0039 & 0.3064 & 0.5971 \\
$X_{1} X_{3}$ & 0.0039 & 1 & 0.0039 & 0.3064 & 0.5971 \\
$X_{2} X_{3}$ & 0.0007 & 1 & 0.0007 & 0.0530 & 0.8245 \\
$X_{1}^{2}$ & 0.0088 & 1 & 0.0088 & 0.6928 & 0.4327 \\
$X_{2}^{2}$ & 0.0076 & 1 & 0.0076 & 0.5980 & 0.4646 \\
$X_{3}^{2}$ & 0.3302 & 1 & 0.3302 & 25.90 & 0.0014 \\
Residual & 0.0892 & 7 & 0.0127 & & \\
Lack of Fit & 0.0575 & 3 & 0.0192 & 2.41 & 0.2071 \\
Pure Error & 0.0318 & 4 & 0.0079 & & \\
Cor Total & 1.24 & 16 & & & \\
$R^{2}$ & 0.9279 & & & &
\end{tabular}

Table 7. Analysis of variance (ANOVA) for the response surface quadratic model for antioxidant activity (\%DPPH).

\begin{tabular}{cccccc}
\hline Source & Sum of Squares & df & Mean Square & $\boldsymbol{F}$-Value & $p$-Value \\
\hline Model & 2499.90 & 9 & 277.77 & 5.14 & 0.0211 \\
$X_{1}$-Temperature & 834.36 & 1 & 834.36 & 15.44 & 0.0057 \\
$X_{2}$-Time & 22.22 & 1 & 22.22 & 0.4111 & 0.5418 \\
\hline
\end{tabular}


Table 7. Cont.

\begin{tabular}{cccccc}
\hline Source & Sum of Squares & df & Mean Square & F-Value & $p$-Value \\
\hline$X_{3}$-Water content & 113.21 & 1 & 113.21 & 2.09 & 0.1911 \\
$X_{1} X_{2}$ & 40.76 & 1 & 40.76 & 0.7541 & 0.4140 \\
$X_{1} X_{3}$ & 164.27 & 1 & 164.27 & 3.04 & 0.1248 \\
$X_{2} X_{3}$ & 118.20 & 1 & 118.20 & 2.19 & 0.1827 \\
$X_{1}^{2}$ & 461.47 & 1 & 461.47 & 8.54 & 0.0223 \\
$X_{2}^{2}$ & 376.34 & 1 & 376.34 & 6.96 & 0.0335 \\
$X_{3}^{2}$ & 244.66 & 1 & 244.66 & 4.53 & 0.0709 \\
Residual & 378.38 & 7 & 54.05 & & \\
Lack of Fit & 201.49 & 3 & 67.16 & 1.52 & 0.3389 \\
Pure Error & 176.89 & 4 & 44.22 & & \\
Cor Total & 2878.28 & 16 & & & \\
$R^{2}$ & 0.8685 & & & & \\
\hline
\end{tabular}

Catechin shows the same trend as theobromine, where only the linear effect of the water content $(p=0.0302)$ as well as the quadratic effect of the temperature $(p=0.0059)$ had a significant influence (Table 5). The model F-value of 3.80 implies the model is significant. There is only a $4.61 \%$ chance that an F-value this large could occur due to noise. $p$-values less than 0.05 indicate model terms are significant like in this case. The Lack of Fit F-value of 2.20 implies the Lack of Fit is not significant relative to the pure error. Nonsignificant lack of fit $(p=0.2306)$ is good and implies the good model fitting.

The model F-value of 10.01 implies the model for caffeine is significant (Table 6). There is only a $0.31 \%$ chance that an F-value this large could occur due to noise. The model $p$-value is less than 0.05 , indicating that model is statistically significant. In this case, the linear term of water content $\left(X_{3}\right)$ as well as quadratic term $\left(\mathrm{X}_{3}{ }^{2}\right)$ are significant model terms for caffeine content. The Lack of Fit F-value of 2.41 implies the Lack of Fit is not significant relative to the pure error. There is a $20.71 \%$ chance that a Lack of Fit F-value this large could occur due to noise. Nonsignificant lack of fit in the case of caffeine is desirable.

ANOVA for antioxidant activity (Table 7) in CBS extracts show that model is significant $(p=0.0211)$ and that linear term of temperature $\left(X_{1}\right)$ as well as quadratic term of temperature $\left(X_{1}{ }^{2}\right)$ and time $\left(X_{2}^{2}\right)$ influenced significantly of investigated response. In this case, water content had no significant influence. The lack of fit F-value of 1.52 implies the lack of fit is not significant relative to the pure error.

Summarizing all the obtained results, it can be concluded that water content had the strongest influence on all investigated active compounds in CBS extracts ( $p$-value is $<0.05$ ), whereas the extraction temperature only influenced an antioxidant activity.

Three-dimensional plots are given for theobromine in Figure 1, for caffeine in Figure 2, and for catechin in Figure 3. For two most abundant methylxanthines in CBS three dimensional plots (Figure 1 and Table 2) showed very similar shapes. The plots show that by increasing water content, concentration of those two compounds significantly increase. As theobromine has a limited solubility in water [23], two opposite effects of water probably influenced its extractability. It could be assumed that the higher content of water decreases theobromine extractability due to its lower solubility, whereas at the same time, it causes a lower viscosity of the solvent, thus increasing its diffusion from the CBS. In addition, when water is added in higher amounts to the DES, it decreases a hydrogen bond formation between DES and the bioactive compound, thus decreasing its extractability [43]. Opposite to that, temperature and extraction time had no significant influence on methylxantine concentrations in obtained CBS extracts. All three parameters (water content, time, and temperature) significantly influenced on the DPPH scavenging activity (Figure 4). The increased DPPH activity can be attributed to the higher amount of antioxidants in the extracts. Bajkacz et al. [44] stated that the increase in water content (more than 10\%) in DES increased the flavonoid recovery from food samples. According to them, the best yields were obtained with $30 \%$ water content, while the further increase up to $75 \%$ decreased the flavonoid content. 


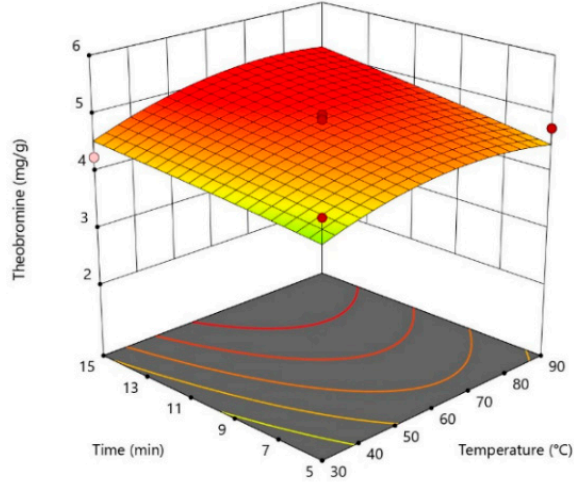

(a)

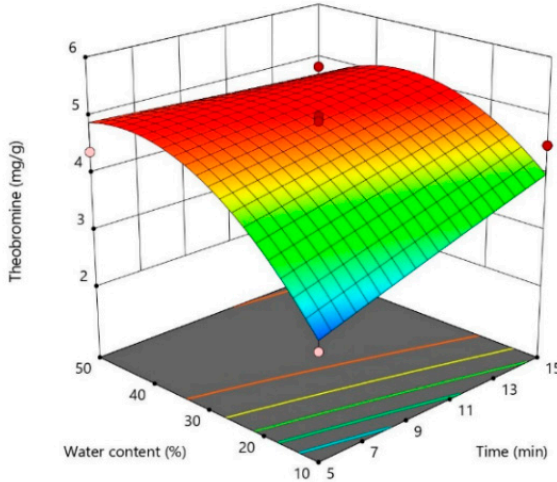

(b)

Figure 1. Three-dimensional plot for theobromine content in cocoa shell extracts as a function of extraction time and temperature (a). Three-dimensional plot for theobromine content in cocoa shell extracts as a function of water content and extraction time (b).

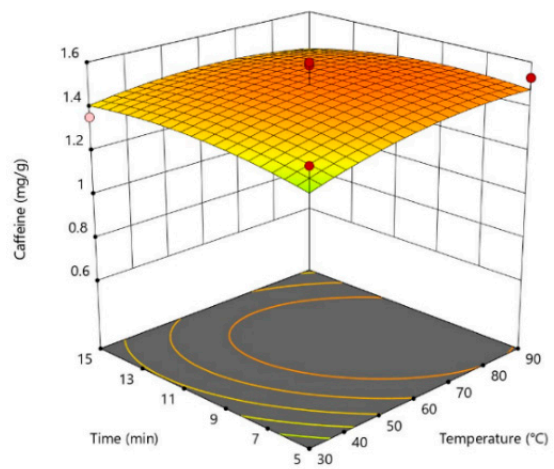

(a)

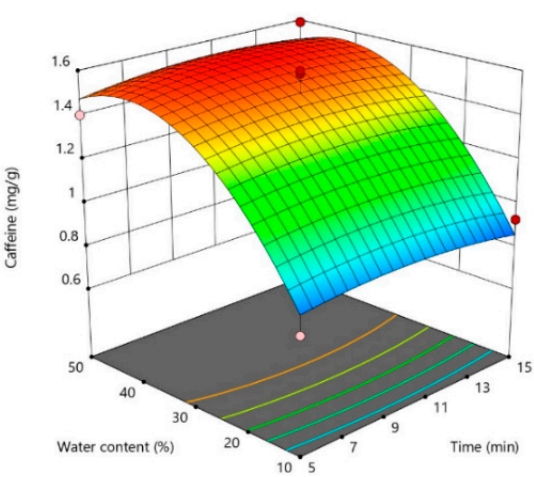

(b)

Figure 2. Three-dimensional plot of caffeine content in cocoa shell extracts as a function of extraction time and temperature (a). Three-dimensional plot of caffeine in cocoa shell extracts as a function of water content and extraction time $(\mathbf{b})$.

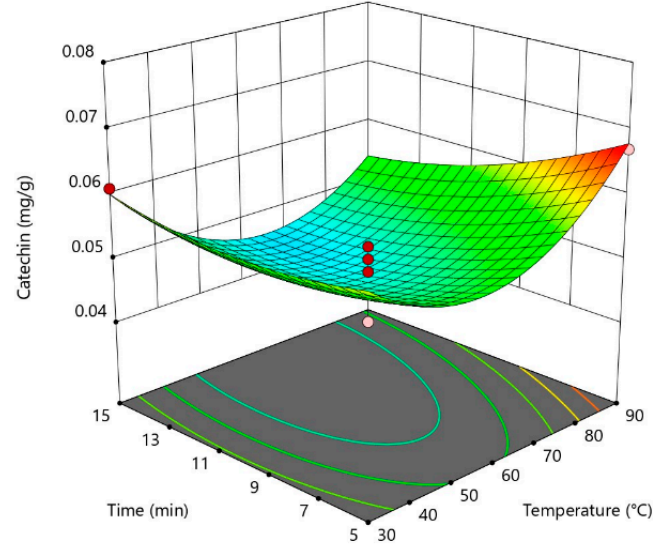

(a)

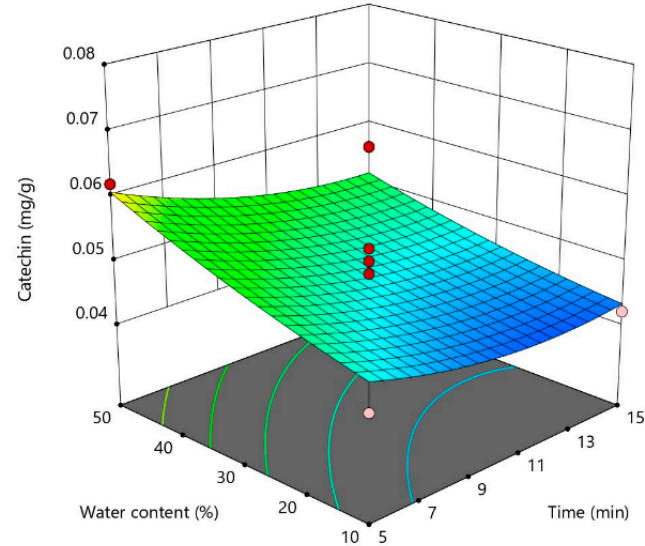

(b)

Figure 3. Three-dimensional plot of catechin content in cocoa shell extracts as a function of extraction time and temperature (a). Three-dimensional plot of catechin in cocoa shell extracts as a function of water content and extraction time (b). 


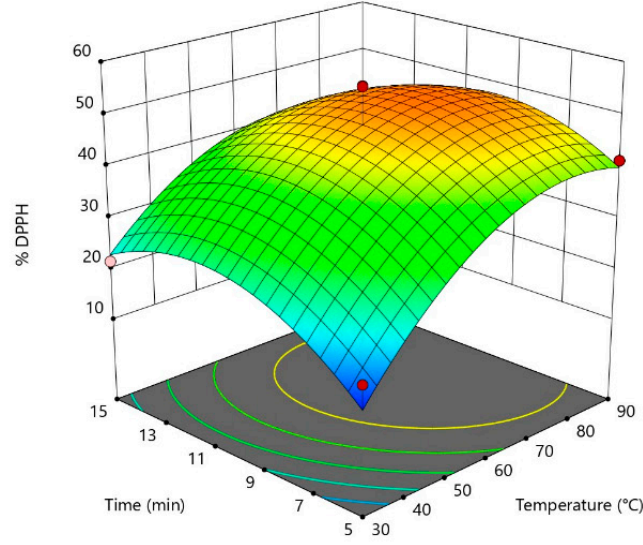

(a)

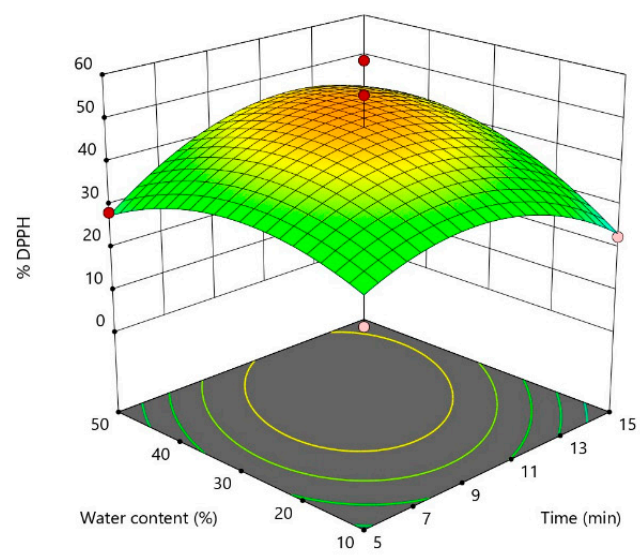

(b)

Figure 4. Three-dimensional plot of \% DPPH in cocoa shell extracts as a function of extraction time and temperature (a). Three-dimensional plot of \% DPPH in cocoa shell extracts as a function of water content and extraction time (b).

The equations, in terms of coded factors (Table 8), can be used to make predictions about the response for given levels of each factor. By default, the high levels of the factors are coded as +1 and the low levels are coded as -1 . The coded equation is useful for identifying the relative impact of the factors by comparing the factor coefficients.

Table 8. Polynomial equations calculated after implementation of BBD (in terms of coded factors).

\begin{tabular}{|c|c|}
\hline Regresion Coefficient & 2nd Order Polynomial Equation \\
\hline Theobromine $\left(\mathrm{Y}_{1}\right)$ & $\begin{array}{c}4.90+0.2309 X_{1}+0.2620 X_{2}+0.7129 X_{3}-0.2896 X_{1}^{2}-0.0173 X_{2}^{2}-0.8301 X_{3}^{2}+ \\
0.0793 X_{1} X_{2}-0.1460 X_{1} X_{3}-0.3902 X_{2} X_{3}\end{array}$ \\
\hline Caffeine $\left(\mathrm{Y}_{2}\right)$ & $\begin{array}{c}1.50+0.0365 X_{1}+0.0009 X_{2}+0.3099 X_{3}-0.0458 X_{1}^{2}-0.0426 X_{2}^{2}-0.2800 X_{3}^{2} \\
-0.0312 X_{1} X_{2}-0.0313 X_{1} X_{3}+0.0130 X_{2} X_{3}\end{array}$ \\
\hline Catechin $\left(\mathrm{Y}_{3}\right)$ & $\begin{array}{c}0.0474+0.0005 X_{1}-0.0034 X_{2}+0.0054 X_{3}+0.0107 X_{1}^{2}+0.0024 X_{2}^{2}+ \\
0.0009 X_{3}^{2}-0.0035 X_{1} X_{2}-0.0065 X_{1} X_{3}-0.0013 X_{2} X_{3}\end{array}$ \\
\hline $\mathrm{DPPH}\left(\mathrm{Y}_{4}\right)$ & $\begin{aligned} 48.14+10.21 X_{1}+1.67 X_{2}+ & 3.76 X_{3}-10.47 X_{1}^{2}-9.45 X_{2}^{2}-7.62 X_{3}^{2}-3.19 X_{1} X_{2} \\
& -6.41 X_{1} X_{3}+5.44 X_{2} X_{3}\end{aligned}$ \\
\hline
\end{tabular}

$X_{1}$ : temperature; $X_{2}$ : time; $X_{3}$ : water content

The optimization procedure is the fundamental tool in extraction processes; therefore, in this study, considering the maximum and by applying desirability function method, the optimal conditions for DES/MAE of CBS were estimated to be at time $11.410 \mathrm{~min}$, temperature $35.106{ }^{\circ} \mathrm{C}$, and using water content $49.392 \%$. Under these optimal conditions given by desirability function method and considering the maximum, theobromine concentration would be $4.485 \mathrm{mg} / \mathrm{g}$, caffeine $1.509 \mathrm{mg} / \mathrm{g}$, catechin $0.0654 \mathrm{mg} / \mathrm{g}$, caffeic acid $0.137 \mathrm{mg} / \mathrm{g}$, and DPPH scavenging activity $36.042 \%$. Predicted data were experimentally verified with good agreement between predicted and experimental values with a deviation of $\pm 5 \%$, which confirms significance of proposed model.

\section{Conclusions}

The combination of extraction with DESs and MAE of CBS for the purpose of isolation targeted bioactive compounds proved to be highly efficient. The results showed how only the water content in DES significantly influenced the extraction of methylxantines (theobromine and caffeine) from CBS, whereas the linear effect of the water content as well as the quadratic effect of the temperature had a significant influence on catechin. On the DPPH scavenging activity, linear and quadratic terms of temperature as well as quadratic term of time have statistically significantly influence. The study proves how these novel green extraction methods could definitely be included in the future trends 
of supplying and producing enriched extracts especially from food by-products like CBS which accumulation is increasingly problem in today's world. Obtained extracts rich in various bioactive compounds could further be used as a raw material in food, pharmaceutical, and chemical industries.

Author Contributions: Conceptualization, S.J. and M.M; methodology, N.P. and M.J.; formal analysis, M.M.; investigation, M.M., N.P., and M.J., resources, S.J. and M.M., data curation, M.M.; writing-original draft preparation N.P., M.M., and M.B.; writing-review and editing, N.P., M.M., S.J., and M.B.; visualization M.M., and S.J., supervision, S.J. and M.M.; project administration, S.J. and M.B. All authors have read and agreed to the published version of the manuscript.

Funding: This research was funded by Croatian Science Foundation under the project "Application of innovative techniques of the extraction of bioactive components from by-products of plant origin" (UIP-2017-05-9909).

Acknowledgments: This work was supported in part by Croatian Science Foundation under the project "Application of innovative techniques of the extraction of bioactive components from by-products of plant origin" (UIP-2017-05-9909) and as part of the "Atrium of Knowledge" project co-financed by the European Union from the European Regional Development Fund and the Operational Programme Competitiveness and Cohesion 2014-2020.

Conflicts of Interest: The authors declare no conflicts of interest.

\section{References}

1. Hernández-Hernández, C.; Morales-Sillero, A.; Fernández-Bolaños, J.; Bermúdez-Oria, A.; Morales, A.A.; Rodríguez-Gutiérreza, G. Cocoa bean husk: industrial source of antioxidant phenolic extract. J. Sci. Food Agric. 2019, 99, 325-333. [CrossRef]

2. Okiyama, D.C.G.; Navarro, S.L.B.; Rodrigues, C.E.C. Cocoa shell and its compounds: Applications in the food industry. Trends Food Sci. Tech. 2017, 63, 103-112. [CrossRef]

3. Hartati, I. Hydrotropic extraction of theobromine from cocoa bean shell. Momentum 2010, 6, 17-20.

4. Bentil, J.A.; Dzogbefia, V.P.; Alemawor, F. Enhancement of the nutritive value of cocoa (Theobroma cacao) bean shells for use as feed for animals through a two-stage solid state fermentation with Pleurotus ostreatus and Aspergillus niger. Int. J. Appl. Microbiol. Biotechnol. Res. 2015, 3, 20-30.

5. Hamzat, R.A.; Adeola, O. Chemical Evaluation of Co-products of Cocoa and Kola as Livestock Feeding Stuffs. J. Anim. Sci. Adv. 2011, 1, 61-68.

6. Adeloye, A. Efficiencies of Conversion of Some Lignocellulosic Waste Materials by Goats. Bioresour. Technol. 1992, 40, 167-169. [CrossRef]

7. Adebowale, B.A.; Olubamiwa, O. Growth Response of Clarias gariepinus juvenile to Cocoa Husk Endocarp Based Diets. Agric. J. 2008, 3, 425-428.

8. Falaye, A.E.; Jauncey, K. Acceptability and digestibility by tilapia Oreochromis niloticus of feeds containing cocoa husk. Aquac. Nutr. 1999, 5, 157-161. [CrossRef]

9. Magistrelli, D.; Zanchi, R.; Malagutti, L.; Galassi, G.; Canzi, E.; Rosi, F. Effects of Cocoa Husk Feeding on the Composition of Swine Intestinal Microbiota. J. Agric. Food Chem. 2016, 64, 2046-2052. [CrossRef]

10. Bernaert, H.; De Ruysscher, I. Methods for Extraction Cocoa. U.S. Patent US 2013/0302473 A1, 14 November 2013.

11. Jozinović, A.; Panak Balentić, J.; Ačkar, Đ.; Babić, J.; Pajin, B.; Miličević, B.; Guberac, S.; Šubarić, D. Cocoa husk application in enrichment of extruded snack products. In Proceedings of the Fourth International Congress on Cocoa Coffee and Tea, Torino, Italy, 25-28 June 2017; Elsevier: Torino, Elsevier; p. 68.

12. Sanchez Mundo, M.L.; Jaramillo Flores, M.E.; Espinosa Solis, V.; Chávez-Reyes, Y.; Díaz Ramírez, M.; Salgado Cruz, M.P.; Calderón Domínguez, G. Muffins enriched with cocoa shell fiber. In Proceedings of the Fourth International Congress on Cocoa Coffee and Tea, Torino, Italy, 25-28 June 2017; Elsevier: Torino, Elsevier; p. 124.

13. Sanchez Mundo, M.L.; Martínez Mendez, D.; Chávez-Reyes, Y.; Espinosa-Solis, V.; Jaramillo-Flores, M.-E.; Torruco-Uco, J.G. Chemical and nutritional characteristics of biscuits added with cocoa shell powder. In Proceedings of the Fourth International Congress on Cocoa Coffee and Tea, Torino, Italy, 25-28 June 2017; Elsevier: Torino, Elsevier; p. 124.

14. Ooshima, T.; Osaka, Y.; Sasaki, H.; Osawa, K.; Yasuda, H.; Matsumura, M.; Sobue, S.; Matsumoto, M. Caries inhibitory activity of cacao bean husk extract in in-vitro and animal experiments. Arch. Oral Biol. 2000, 45, 639-645. [CrossRef] 
15. Matsumoto, M.; Tsuji, M.; Okuda, J.; Sasaki, H.; Nakano, K.; Osawa, K.; Shimura, S.; Ooshima, T. Inhibitory effects of cacao bean husk extract on plaque formation in vitro and in vivo. Eur. J. Oral Sci. 2004, 112, $249-252$. [CrossRef] [PubMed]

16. Castillejo, G.; Bulló, M.; Anguera, A.; Escribano, J.; Salas-Salvadó, J. A controlled, randomized, double-blind trial to evaluate the effect of a supplement of cocoa husk that is rich in dietary fiber on colonic transit in constipated pediatric patients. Pediatrics 2006, 118, 641-648. [CrossRef] [PubMed]

17. Nawrot, P.; Jordan, S.; Eastwood, J.; Rotstein, J.; Hugenholtz, A. Effects of caffeine on human health. Food Addit. Contam. 2003, 20,1-30. [CrossRef] [PubMed]

18. Panak Balentić, J.; Ačkar, Đ.; Jokić, S.; Jozinović, A.; Babić, J.; Miličević, B.; Šubarić, D.; Pavlović, N. Cocoa shell: A by-product with great potential for wide application. Molecules 2018, 23, 1404. [CrossRef]

19. Jokić, S.; Gagić, T.; Knez, Ž.; Šubarić, D.; Škerget, M. Separation of active compounds from food by-product (cocoa shell) using subcritical water extraction. Molecules 2018, 23, 1408. [CrossRef]

20. Okiyama, D.C.G.; Soares, I.D.; Cuevas, M.S.; Crevelin, E.J.; Moraes, L.A.B.; Melo, M.P.; Oliveira, A.L.; Rodrigues, C.E.C. Pressurized liquid extraction of flavanols and alkaloids from cocoa bean shell using ethanol as solvent. Food Res. Int. 2018, 114, 20-29. [CrossRef]

21. Karim, A.A.; Azlan, A.; Ismail, A.; Hashim, P. Antioxidant properties of cocoa pods and shells. Malaysian Cocoa J. 2014, 8, 49-56.

22. Grillo, G.; Boffa, L.; Binello, A.; Mantegna, S.; Cravotto, G.; Chemat, F.; Dizhbite, T.; Lauberte, L.; Telysheva, G. Cocoa bean shell waste valorisation; extraction from lab to pilotscale cavitational reactors. Food Res. Int. 2019, 115, 200-208. [CrossRef]

23. Nguyen, V.T.; Nguyen, N.H. Proximate composition, extraction, and purification of theobromine from cacao pod husk (Theobroma Cacao, L.). Technologies 2017, 5, 14. [CrossRef]

24. Arlorio, M.; Coïsson, J.D.; Travaglia, F.; Varsaldi, F.; Miglio, G.; Lombardi, G.; Martelli, A. Antioxidant and biological activity of phenolic pigments from Theobroma cacao hulls extracted with supercritical $\mathrm{CO}_{2}$. Food Res. Int. 2005, 38, 1009-1014. [CrossRef]

25. Pavlović, N.; Jakovljević, M.; Miškulin, M.; Molnar, N.; Ačkar, Đ.; Jokić, S. Green extraction techniques of bioactive components from cocoa shell. Croat. J. Food Sci. Technol. 2019, 11, 11-20. [CrossRef]

26. Azmir, J.; Zaidul, I.S.M.; Rahman, M.M.; Sharif, K.M.; Mohamed, A.; Sahena, F.; Jahurul, M.H.A.; Ghafoor, K.; Norulaini, N.A.N.; Omar, A.K.M. Techniques for extraction of bioactive compounds from plant materials: A review. J. Food Eng. 2013, 117, 426-436. [CrossRef]

27. Cunha, S.C.; Fernandes, J. Extraction techniques with deep eutectic solvents. Trends Anal. Chem. 2018, 105, 225-239. [CrossRef]

28. García, A.; Rodríguez-Juan, E.; Rodríguez-Gutiérrez, G.; Rios, J.J.; Fernández-Bolaños, J. Extraction of phenolic compounds from virgin olive oil by deep eutectic solvents (DESs). Food Chem. 2016, 197, 554-561. [CrossRef] [PubMed]

29. Cvjetko Bubalo, M.; Ćurko, N.; Tomašević, M.; Kovačević Ganić, K.; Radojćić Redovniković, I. Green extraction of grape skin phenolics by using deep eutectic solvents. Food Chem. 2016, 200, 159-166. [CrossRef]

30. Fraige, K.; Arrua, R.D.; Sutton, A.T.; Soleo Funari, C.; Cavalheiro, A.J.; Hilder, E.F.; da Silva Bolzani, V. Using natural deep eutectic solvents for the extraction of metabolites in Byrsonima. J. Sep. Sci. 2018, 42, 591-597. [CrossRef] [PubMed]

31. Zhao, B.-Y.; Xu, P.; Yang, F.-X.; Wu, H.; Zong, M.-H.; Lou, W.-Y. Biocompatible deep eutectic solvents based on choline chloride: characterization and application to the extraction of rutin from Sophora japonica. ACS Sustain. Chem. Eng. 2015, 3, 2746-2755. [CrossRef]

32. Molnar, M.; Jakovljević, M.; Jokić, S. Optimization of the process conditions for the extraction of rutin from Ruta graveolens L. by choline chloride based deep eutectic solvents. Solvent Extr. Res. Dev. 2018, 25, 109-116. [CrossRef]

33. Jiang, Z.-M.; Wang, L.-J.; Gao, Z.; Zhuang, B.; Yin, Q.; Liu, E.-H. Green and efficient extraction of different types of bioactive alkaloids using deep eutectic solvents. Microchem. J. 2019, 145, 345-353. [CrossRef]

34. Chizoba Ekezie, F.-G.; Sun, D.-W.; Cheng, J.-H. Acceleration of microwaveassisted extraction processes of food components by integrating technologies and applying emerging solvents: A review of latest developments. Trends Food Sci. Tech. 2017, 67, 160-172. [CrossRef] 
35. Jokić, S.; Šafranko, S.; Jakovljević, M.; Cikoš, A.-M.; Kajić, N.; Kolarević, F.; Babić, J.; Molnar, M. Sustainable Green Procedure for Extraction of Hesperidin from Selected Croatian Mandarin Peels. Processes 2019, 7, 469. [CrossRef]

36. de Oliveira Nascimento, D.A.; Raffin, R.P.; de Oliveira Fogaça, A.; de Moraes, C.M.B.; Boligon, A.; Ferreira Ourique, A. Evaluation of the antioxidant activity by the DPPH radical scavenging method of free and liposome-associated cocoa extracts. Disciplinarum Scientia 2016, 17, 375-386.

37. Jokić, S.; Bijuk, M.; Aladić, K.; Bilić, M.; Molnar, M. Optimisation of supercritical $\mathrm{CO}_{2}$ extraction of grape seed oil using response surface methodology. Int. J. Food Sci. Tech. 2016, 51, 403-410. [CrossRef]

38. de la Hoz, A.; Diaz-Ortiz, A.; Moreno, A. Microwaves in Organic Synthesis. Thermal and Non-Thermal Microwave Effects. Chem. Soc. Rev. 2005, 34, 164-178. [CrossRef]

39. Adamafio, N.A. Theobromine toxicity and remediation of cocoa by-products: An overview. J. Biol. Sci. 2013, 13, 570-576. [CrossRef]

40. Arlorio, M.; Coisson, J.D.; Restani, P.; Matelli, A. Characterization of pectins and some secondary compounds from Theobroma cacao hulls. J. Food Sci. 2001, 66, 653-656. [CrossRef]

41. Sotelo, A.; Alvarez, R.G. Chemical composition of wild Theobroma species and their comparison to the cacao bean. J. Agric. Food Chem. 1991, 39, 1940-1943. [CrossRef]

42. Nair, K.P.P. The agronomy and economy of important tree crops of the developing world, 1st ed.; Elsevier Science: London, Great Britain, 2010; pp. 131-180. [CrossRef]

43. Cai, C.; Li, F.; Liu, L.; Tan, Z. Deep eutectic solvents used as the green media for the efficient extraction of caffeine from Chinese dark tea. Sep. Purif. Technol. 2019, 227, 115723. [CrossRef]

44. Bajkacz, S.; Adamek, J. Development of a method based on natural deep eutectic solvents for extraction of flavonoids from food samples. Food Anal. Methods 2018, 11, 1330-1344.

(C) 2020 by the authors. Licensee MDPI, Basel, Switzerland. This article is an open access article distributed under the terms and conditions of the Creative Commons Attribution (CC BY) license (http://creativecommons.org/licenses/by/4.0/). 